\title{
Periprostetik eklem enfeksiyonları - tek aşama revizyon
}

\author{
Periprosthetic joint infections - single-stage revision
}

\author{
Akos Zaharr ${ }^{1}$, Daniel Kendoff ${ }^{1}$, Safa Gürsoy², Mustafa Akkaya ${ }^{2}$ \\ ${ }^{1}$ Helios ENDO Klinik Hamburg, Germany \\ ${ }^{2}$ Yenimahalle Eğitim ve Araştırma Hastanesi, Ortopedi ve Travmatoloji Kliniği, Ankara
}

\begin{abstract}
Revizyon diz artroplastisi, günümüzde artan primer diz artroplastisi sayılarına bağlı olarak daha fazla görülmektedir. Özellikle periprostetik eklem enfeksiyonları halen revizyon diz artroplastisinde en önemli sorunların başında gelir. Enfeksiyon tanısı sonrası tek ya da iki aşamalı revizyon kararı vermeden önce, hastanın kliniği ayrıntılı bir şekilde değerlendirilmelidir. Uygun olgularda, iyi bir cerrahi öncesi planlama ile tek aşamalı revizyon diz artroplastisinde oldukça başarılı sonuçlar alınabilir.
\end{abstract}

Anahtar sözcükler: diz artroplastisi, total; cerrahi düzeltme, tek aşamalı
Revision knee arthroplasty is conducted more frequently in our day, due to the increasing number of primary knee arthroplasty. Periprosthetic joint infections, in particular, are still one of the major problems of revision knee arthroplasty. Before deciding to conduct a single or two-stage revision following diagnosis of infection, it is required to have a detailed clinical examination of the patient. In appropriate cases, single-stage revision knee arthroplasty after a good preoperative planning can lead to quite successful outcomes.

Key words: knee arthroplasty, total; surgical revision, single-stage
T otal eklem artroplastileri sonrası, enfeksiyon en ciddi komplikasyonlardan biri olarak karşımıza çıkmaktadır. Doğru cerrahi yaklaşımlar, uygun antibiyotik proflaksileri ve diğer tüm önlemlere rağmen, periprostetik eklem enfeksiyonları revizyon cerrahilerinin de en önemli nedenleri arasındadır. Yapılan çalışmalarda, total kalça artroplastisi sonrası enfeksiyon oranları \%1-3 arasında değişmektedir. ${ }^{[1,2]}$ Periprostetik enfeksiyonların erken tanı ve tedavisi, enfeksiyonun kronik hale gelmemesi; tekrarlayan cerrahilerin, artan maliyetlerin, yüksek mortalite ve morbiditenin engellenmesi açısından önemlidir. ${ }^{[3,4]}$

Artroplasti uygulamalarının yaygınlaştığı yıllardan bu yana, derin periprostetik enfeksiyonların tedavisindeki en uygun yaklaşım konusundaki tartışmalar sürmektedir. ${ }^{[5-7]}$ Enfekte komponentlerin çıkarıldığı ve protezsiz bir dönemin ardından revizyon komponentlerin re-implante edildiği iki seans revizyon cerrahisi, bu tekniklerden biri olarak altın standart hale gelmiştir. ${ }^{6]}$ Ancak, iki seanslı revizyon, hastalar tarafından tolere edilmesi zor olan yüksek mortalite ve morbiditeye sahiptir. Aynı zamanda da, implantsız geçen ara dönemde meydana gelen doku değişiklikleri, re-implantasyon sonrası önemli fonksiyonel eksikliklere neden olabilmektedir. ${ }^{[5,6,8,9]}$ Bu nedenle, hastaların uygun olduğu durumlarda tek seans revizyona olan ilgi gittikçe artmaktadır. ${ }^{[10-14]}$ Tek seans revizyonun savunucuları, uygun debridmanın öncelikli olduğunu ve bunun enfeksiyonun çözümünde en önemli etmen olduğunu belirtmektedirler.[11,15] Tek seans revizyonun daha az mortalite, morbitide ve fonksiyonel gerileme ile birlikte tekrarlayan hastaneye yatışları azaltması ile birlikte, maliyetleri önemli oranda düşürdüğü söylenebilir. ${ }^{[5,11,12,16-18]}$

Bu derlemede; tek seans revizyon cerrahisinin ilerlemesinde önemli katkıları olan ve bu alanda 30 yılı aşan bir tecrübeye sahip ENDO-Klinik uygulamalarına yer verilerek, tek seans revizyon sonrası hedeflenen başarıya ulaşmak için gerekenler anlatılmaktadır.

\section{ETIYOLOJI VE SINIFLAMA}

Periprostetik enfeksiyonların tümü, vücuda yabancı bir implant ile ilişkilidir ve diğer kemik enfeksiyonlarından ayırt edilmelidir.

- Illetişim adresi: Dr. Safa Gürsoy, Yenimahalle Eğitim ve Araştırma Hastanesi, Ortopedi ve Travmatoloji Kliniği, Yenimahalle, Ankara Tel: 0505 - 4896632 e-posta: safagursoy@yahoo.com

- Geliștarihi: 8 Nisan $2015 \quad$ Kabul tarihi: 8 Nisan 2015 
İnsan florasından kaynaklanan mikroorganizmaların büyük çoğunluğu, operasyon sırasında implant yüzeyine tutanmaya çalışır. İlk yıl içinde ortaya çıkan enfeksiyonların ise \%90', operasyon sırasında meydana gelen bu kontaminasyondan kaynaklanır. ${ }^{[19]}$ Hematojen enfeksiyonlar daha az sıklıktadır. Yabancı bir cisim varlığında, 100 CFU (colony-forming units) enfeksiyonu tetiklemekte yeterli iken, bu rakam yabancı cisim olmadığı durumlarda 10.000 CFU'dur. ${ }^{[20]}$ Bunun nedeni, yabancı cisim varlığında lökositlerin fagositöz kapasitesinin azalmasıdır. ${ }^{[21,22]}$

Ayrıca, bakteriler biyofilm formasyonu oluşturarak implant yüzeyine tutunabilir. Bu bakteriler, biyofilm ile birlikte, antimikrobiyal ajanlara ve minimal inhibitör konsantrasyona karşı 1000 kata kadar daha dirençli hale gelebilir. ${ }^{[23]}$

Kolonizasyondan, enfeksiyonun klinik olarak tanı konulabileceği aşamaya gelene kadar geçen süre, aylar hatta yıllar sürebilir. Enfeksiyonun lokal işaretleri geç ortaya çıkabilir. Periprostetik enfeksiyonun sadece implant yüzeyinde kendini gösteren bir durum olmadığı, aynı zamanda tüm kemik ve yumuşak dokuyu kaplayan bir patoloji olduğu da bilinmelidir.

Periprostetik enfeksiyonları bazı alt gruplara ayırmak, enfeksiyonun ortaya çıkış zamanına göre farklı tedavi yaklaşımlarının belirlenmesi için önemlidir. Fitzgerald ve arkadaşlarının ${ }^{[24]}$ yapmış oldukları ve Toms ve arkadaşlarının bazı modifikasyonlar eklediği sınıflama sistemi, enfeksiyonun ortaya çıkış şeklinin, zamanlamasının ve uygun tedavi yaklaşımının belirlenmesi açısından kullanışıIırı. ${ }^{[26]}$ Bu sınıflamaya göre: Evre I, akut olarak operasyondan sonra ilk altı hafta içinde görülen; Evre II, altı haftadan sonra kronik, gecikmiş görülen; Evre III, fonksiyonel bir eklem replasmanında hematojen yol ile akut olarak ortaya çıkan; Tsukayama ve arkadaşla$\mathrm{rI}^{[25]}$ tarafından daha önce tanımlanmış olan Evre IV ise başka nedenlerle revizyon uygulanan hastadan cerrahi sırasında alınan kültürlerde pozitifliğin ortaya çıktığı enfeksiyon durumlarıdır.

\section{TANI}

Total eklem sonrası oluşabilecek erken enfeksiyonun ilk semptomları, ameliyat sonrası genellikle ilk 4-8 gün arasında ortaya çıkar. Pürülan akıntı varlığında da enfeksiyon net olarak düşünülmelidir. Ne var ki, 12 günden uzun süren yara akıntısı, yumuşak dokuda kızarıklık ve endürasyon, yarada açılma, mutlaka ciddiye alınmalıdır. Böyle durumlarda, cerrahi olarak proaktif ve agresif yaklaşımlar önerilmektedir. Operasyon sonrası ilk üç hafta içinde hastanın taburcu olmasının ardından; yüzeyel cilt iyileşme problemleri, hematom ve seröz akıntı varlığı, derin protez enfeksiyonu ile korele erken enfeksiyonun göstergeleri olabildiği gibi, klinik işaretler her zaman bu kadar açık olmayabilir.

Mevcut kanıtlar ve American Academy of Orthopaedic Surgeons (AAOS) tarafindan ortaya konan pratik klinik ilkeler doğrultusunda, açıklanamayan ağrısı olan tüm eklem replasmanı geçirmiş hastalarda, aşağıdaki cerrahi öncesi testlerin yapılması önerilmektedir. ${ }^{[27]}$

- C-reactive protein (CRP) ve erythrocyte sedimentation rate (ESR)

- Eklem aspirasyonu ve en az 14 günlük mikrobiyolojik kültür (>14 gün antibiyotiksiz dönem) ${ }^{[28]}$

- Sinoviyal sıvıda beyaz kan hücresi ve nötrofil yüzdesi analizi[29-31]

- Klinik semptomlar veya pozitif sürüntü kültürleri varlığında, negatif aspirasyon kültürü durumunda tekrarlayan eklem aspirasyonları

- Belirgin klinik semptomlar varlığında devam eden, negatif kültürler durumunda diz eklem biyopsisi[32]

\section{Eklem Aspirasyonu}

Eklem aspirasyonu, tek seans revizyon planlanan hastada etken bakterinin tanımlanması için en önemli ve elzem ameliyat öncesi tanı aracıdır. Tek seans revizyon sırasında, yüksek terapotik dozda hangi antibiyotikli sementin uygulanacağının belirlenmesi için, pozitif kültür ve güvenilir antibiyogram elde edilmelidir. ${ }^{[33-39]}$

Bu protokol, ENDO-Klinik tarafindan planlanan her revizyonda, tüm erken ya da geç aseptik gevşemelerde ve dahası, beklenmeyen ağrısı ve fonksiyon kaybı olan tüm primer ve revizyon olgularda standart olarak uygulanmaktadır.

ENDO-Klinikte yapılan bir aspirasyon çalışmasında, aseptik nedenlerle revizyon planlanan hastalarda hiçbir klinik enfeksiyon belirteci olmamasına rağmen, \%4-7 oranında düşük gradlı enfeksiyon gösterilmiştir. ${ }^{[40]}$

\section{Görüntüleme}

Seri konvansiyonel radyolojik değerlendirmeler, belirgin kemik enfeksiyon belirteçlerini göstermek açısından kullanışlı olabilmektedir. Periprostetik enfeksiyonların tanısında, ENDO-Klinik yaklaşımı olarak, rutin nükleer görüntüleme kullanılmamaktadır. Lökosit işaretli görüntüleme, Gallium görüntülemesi ve $P E T$ gibi kemik taramalarının, oldukça yüksek çözünürlüklü olmalarına rağmen, yapılan orta güvenilir çalışma verileri ile non-spesifik olduğu gösterilmiştir. ${ }^{[27]}$ Kemik taramaları, eklem replasmanından yıllar sonra ortaya çıkan şüpheli gelişmeleri göstermek için kullanılabilmektedir. 
İmplantasyonun erken fazında ortaya çıkacak değişiklikler, tanı konulmasına engel olacaktır.

Etkilenen eklemin radyolojik olarak tetkik edilmesinin yanı sıra, vücudun diğer implantlı eklemleri de mutlaka radyolojik olarak incelenmelidir.

\section{ENDIKASYONLAR}

Tek seans revizyon protokolünün karşısında çok sayıda argüman bulunmamakla birlikte tüm enfekte vakaların \%85'den fazlasının bu teknik ile başarılı bir şekilde tedavi edilebildiği savunulmaktadır. Bu tekniğin başarısındaki temel altyapı bakterinin kanıtlanmasının ardından deneyimli bir mikrobiyolog tarafindan oluşturulacak hasta bazlı planlanmanın ve uygun sistemik antibiyoterapinin uygulanabilmesidir.

\section{KONTRAENDIKASYONLAR}

Tek seans yerine iki seanslı yaklaşımın tercih edileceği durumlar şu şekilde sıralanmaktadır:

- İkiden fazla başarısız tek seans yaklaşım.

- Damar-sinir paketini içeren enfeksiyon varlı̆̆ı.

- Net olmayan bakteri tanımlaması.

- Uygun antibiyotiğin bulunmaması.

- Yüksek antibiyotik direnci.

\section{AMELIYAT ÖNCESI HAZIRLIK VE PLANLAMA}

Tek seans revizyon yaklaşımına başlamadan önce, pozitif bakteri kültürü olmalı ve güvenilir antibiyotik direnci mutlaka gösterilmelidir. Çimentolu tespitte, yüksek lokal antibiyotik konsantrasyonu elde edilebilecek antibiyotikli çimentolar tercih edilmelidir. ${ }^{[41]} \mathrm{Bu}$ yaklaşımın, ileride, antibiyotik salan çimentosuz implantlarla ve gümüş kaplamalarla tamamlanabileceği düşünülmektedir.

Tek seans yaklaşımların başarısında anahtar noktanın, implantların ve çimentonun çıkarılmasının yanı sıra, enfekte yumuşak dokunun ve kemiğin oldukça agresif ve tam olarak debride edilmesi olduğu unutulmamalıdır. Debridman mutlaka tam sinoviyektomiyi, dizin posterior yapılarını veya kalçanın ön ve arka kapsülünün radikal eksizyonunu içermelidir.

Diz ekleminde radikal bir debridman elde etmek için, bu yaklaşım bazen yan bağların ve geniş yumuşak dokunun feda edilmesine kadar gidebilmektedir. Bunun sonucu olarak, yapılacak cerrahi planlamada cerrahın seçimine bağlı olarak, yarı kısıtlı, tam kısıtlı ya da menteşeli protezlerin tercih edilmesi gerekebilir.

\section{IMPLANT VE ÇIMENTO}

Toz formda antibiyotiklerin ameliyat sırasında antibiyotikli çimentolara ilave edilmesi, tüm olgularda gereklidir. Miktar değişkenlik göstermekle birlikte, karmaşık implant sistemleri ve uygun çimento tabancaları için, en az 80-120 gr çimentoya ihtiyaç vardır. Dar diyafize sahip hastalar için ekstra dar ağızlıklar, uygun retrograd çimentolamaya olanak sağlayacaktır.

İmal edilmiş antibiyotikli çimentolar, genellikle uygun olabilir; ancak, herhangi bir tek seans yaklaşımının başarısı için, hasta bazlı antibiyograma göre hazırlanmış çimento esastır.

\section{AMELIYAT TEKNIĞi}

- Cerrahi başarı, tüm implantların, geriye kalan tüm sement artıklarının, kablo ve tellerin ve kontamine tüm materyallerin çıkarılmasına bağlıdır. Bu işlem için, cerrahi sırasında gerekli tüm ekipmanların hazır olması gerekmektedir.

- Kanama olmayan yumuşak dokular ve ilgili kemikler radikal olarak eksize edilmelidir.

- Mikrobiyolojik ve histolojik incelemeler için, ilgili tüm cerrahi alandan tercihan beş veya altı biyopsi örneği alınmalıdır (Şekil 1).

- Toplam debridman miktarı, genellikle iki seanslı revizyon sırasında uygulananın üzerinde olacaktır.

- Pulsatil basınçlıyıkama önerilmektedir. Debridman sonrası, implantasyon öncesi intramedüller kanal, polimerik biguanid-hydrochlorid (polyhexanid) batırılmış çubuklar ile paketlenir. Ayrıca, hastaya yeniden yara örtüsü uygulamasından önce cilde bu çubuklar yerleştirilir.

- Tüm cerrahi ekip implantasyon öncesi tekrar giyinmeli ve yeni cerrahi ekipmanlar kullanılmalıdır.

- Ikinci doz antibiyotik, 1,5 saatin ardından veya 1 litre kan kaybının ardından tekrar uygulanmalıdır.

\section{REIMPLANTASYON}

Yetersiz kemik stoğu, allogreft kullanımını gerektirebilir (Şekil 2); ancak, ENDO-Klinik uygulaması, genellikle geniş defektlerin antibiyotikli çimento ile doldurulması yönündedir.

Alternatif olarak son yıllarda, ileri poroz teknolojiler ile üretilmiş asetabular kamalar veya femoral ve tibial cone kullanımı yaygındır (Şekil 3). Bu ürünlerin çimentolu protez ile kombine kullanımı mümkündür. Ayrıca, bunların antibakteriyel potansiyeli olduğu düşünülmekle birlikte, klinik olarak henüz kanıtlanmamıştır. 


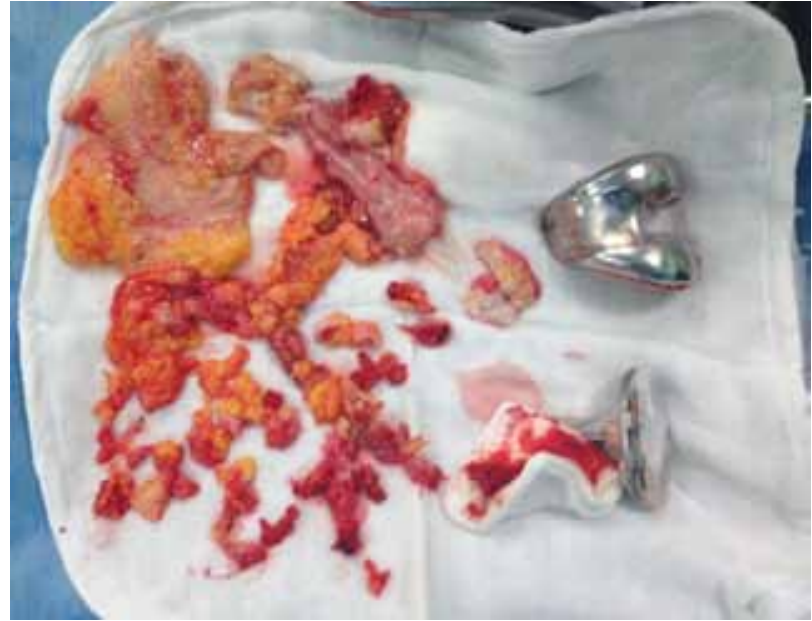

Şekil 1. Tek seans revizyonda radikal debridman sırasında eksize edilen dokular ve implantlar (Prof. Dr. Murat Bozkurt'un arşivinden, izni ile alınmıştır).

Antibiyotikli çimento, aşağıdaki kriterlere uygun olarak hazırlanmalıdır:

- Uygun antibiyotik.

- Bakterisidal etki (klindamisin hariç).

- Toz form (asla sıvı olmayan).

- PMMA tozunun en fazla \%10'u oranında antibiyotik.

- Antibiyotikler (örn., vankomisin). çimentonun polimerizasyonunu değiştirebilir.

- Modern çimentolama teknikleri uygulanmalıdır. Diz replasmanı sırasında iyi bir çimento-kemik arayüzü elde etmek için, çimento uygulaması öncesi turnikenin şişirilmiş olması gerekmektedir.

\section{AMELIYAT SONRASI ANTIBIYYOTIKLER}

Tek seans yaklaşımında, ameliyat sonrası düzenli antibiyotik uygulaması 10-14 gün arasındadır (istisna, streptokoklar). İki aşamalı prosedürde ise, altı haftalık uzatılmış intravenöz antibiyotik uygulaması daha yaygındır. Bu uzun süreli döneme literatürde geçerli bir açıklama getirilememekle birlikte, uzatılmış antibiyotik uygulaması ile ilgili sistemik ve organ-spesifik komplikasyonlara dair açık kanıtlar bulunmaktadır. ${ }^{[42-44]}$

\section{AMELIYAT SONRASI BAKIM VE REHABILITASYON}

ENDO-Klinik uygulamasında, ameliyat sonrası hastanede kalış süresi 12-20 gün (ortalama 14) arasında değişmektedir. Yumuşak doku ve kemik hasarı değişkenliği ve enfeksiyon derecesine bağlı olarak, tek

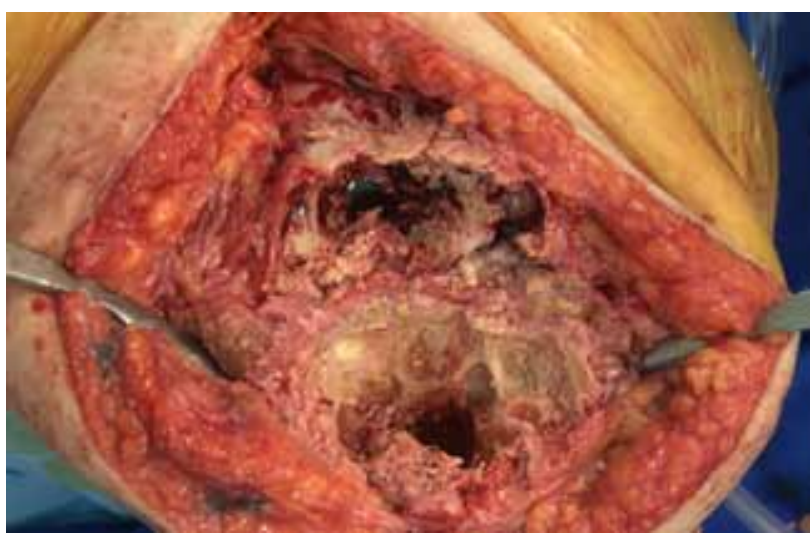

Şekil 2. Debridman sonrası görülen geniş kemik defektleri (Prof. Dr. Murat Bozkurt'un arşivinden, izni ile alınmıştır).

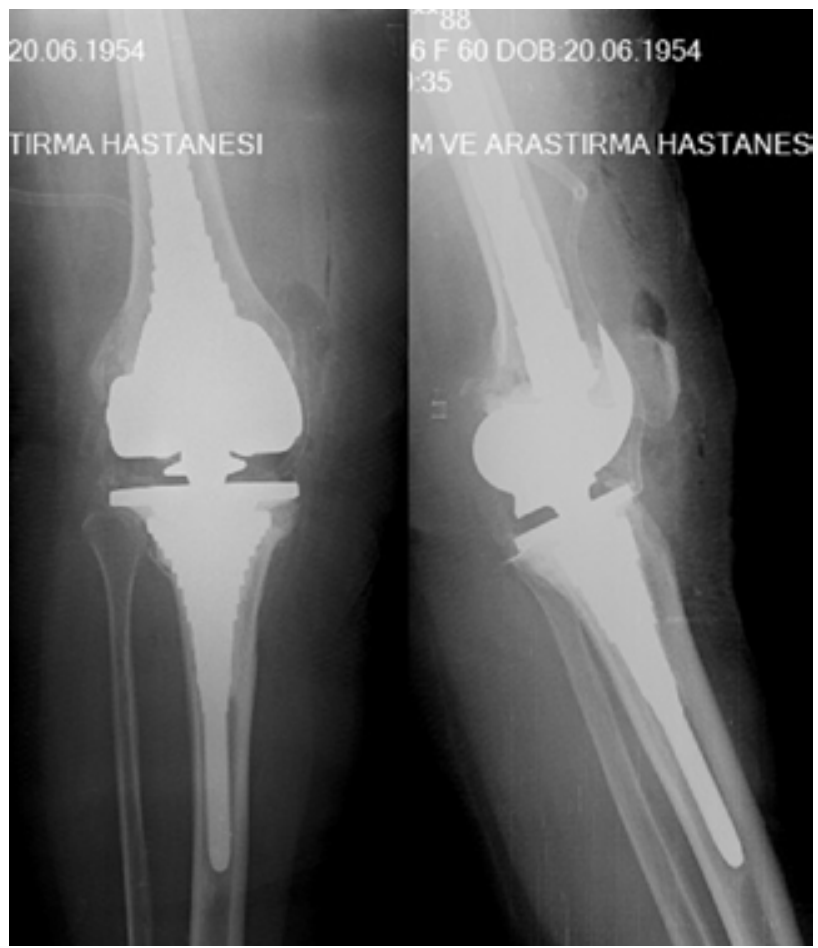

Şekil 3. Geniş kemik defektleri ileri poroz teknolojiler ile üretilmiş femoral ve tibial cone ile doldurulan hastanın anteroposterior ve lateral grafileri (Prof. Dr. Murat Bozkurt'un arşivinden, izni ile alınmıştır).

aşamalı prosedürden sonraki fizyoterapi uygulaması hakkında bir genelleme yapılamaz. Çoğunlukla olguya özgü bir program geliştirilir. Yapısal hasara bağlı immobilizasyon ihtiyacı ile erken hareket verme girişimleri arasındaki denge, özellikle ek hastalığı olan daha yaşlı hastalarda, göz önünde tutulması gereken önemli bir unsurdur. Ancak, eğer mümkünse, ameliyat sonrasındaki sekiz gün içerisinde erken ve hızlı hareket edilmesi sağlanmalıdır. Diz replasmanı hastalarında, esas duruma benzer bir hareketlilik stratejisi, hastaların 
erken iyileşme dönemini tamamlamasını sağlayacaktır. Yeterli kemik stoğu olan birçok hastada, tam yük vermeyi içeren mobilizasyon genellikle mümkündür.

\section{AMELIYAT SONRASI KOMPLIKASYONLAR}

Tek seans tekniğinde, inatçı veya yinelenen enfeksiyon en sık karşılaşılan komplikasyondur. Başarısızlık oranları; iki seans revizyonda dirençli olmayan bakteri varlığında \%9-20 arasında olarak bildirilmekle birlikte, tek seans revizyon verilerinin takip edildiği sekiz yıllık ENDO-Klinik tecrübesi, karşılaştırılabilir sonuçlar vermektedir. ${ }^{[45-48]}$

Sonuç olarak; hastalarla onam aşamasında, olguların \%10-20 arasında tekrarlayan veya yeni bir enfeksiyonun olası riski tartışılmalıdır. Tek seans uygulamasının, iki seanslı uygulama karşısındaki işlevsel sonucunu değerlendiren bir karşılaştırmalı veri sunulamasa da, tek seans revizyon tekniğinin savunucuları, eklem spacer uygulamasına ya da etkilenen eklemin kısmi veya tam olarak hareket ettirilmemesinin daha verimli bir sonuca ulaşacağına inanmamakta; aynı zamanda, siyatik sinire veya peroneal sinire ve ana kan damarlarına doğrudan hasar riski unutulmayıp, tecrübeli bir cerrahın gözetimi altında, böyle genişlemiş bir agresif debridmanın yapılması gerektiğini belirtmektedirler.

\section{KLINIK SONUÇLAR}

Dünyada birçok cerrah tarafından, \%9-20 arasındaki tekrar enfeksiyon oranı ile iki seanslı revizyon tekniği tercih edilmektedir. Tek seans ile ilgili birçok çalışma ENDO-Klinik kaynaklı olmakla vesonuçlar takip süresine bağlı olarak değişmekle birlikte, farklı uluslararası kliniklerden \%75-90 oranında başarı oranları bildirilmektedir. ${ }^{[42,43,48,49]}$

\section{SONUÇ}

Periprostetik enfeksiyonlarda tek seans revizyon, birçok cerrah tarafindan uygulanmakla birlikte, cerraha ve hastaya belirgin avantajlar da sunmaktadır. Başarıya ulaşmasındaki adımlar ise; iyi tanımlanmış ve ayrıntılı bir protokol, efektif aspirasyon, agresif cerrahi sırasında debridmanın ardından çimentolu protez uygulaması ve kısa süreli sistemik antibiyotik uygulamasıdır.

\section{KAYNAKLAR}

1. García S, Soriano A, Esteban P, Almela M, Gallart X, Mensa $J$. Usefulness of adding antibiotic to cement in one stage exchange of chronic infection in total hip arthroplasty. Med Clin (Barc) 2005;125(4):138-9.

2. Schutzer SF, Harris WH. Deep-wound infection after total hip replacement under contemporary aseptic conditions. J Bone Joint Surg Am 1988;70(5):724-7.
3. Barrack RL, Burnett RS, Sharkey P, Parvizi J. Diagnosing an infection: an unsolved problem. Orthopedics 2007;30(9):777-8.

4. Martí-Valls J, Alonso J, Lamarca R, Pinto JL, Auleda J, Girvent R, López E, Miralles R, Ramón R, Saló JM. Effectiveness and cost of total hip replacement in seven hospitals in Catalonia, Spain. Med Clin (Barc) 2000;114 Suppl 2:34-9.

5. Berend KR, Lombardi AV Jr, Morris MJ, Bergeson AG, Adams JB, Sneller MA. Two-stage treatment of hip periprosthetic joint infection is associated with a high rate of infection control but high mortality. Clin Orthop Relat Res 2013;471(2):5108. CrossRef

6. Matthews PC, Berendt AR, McNally MA, Byren I. Diagnosis and management of prosthetic joint infection. BMJ 2009;338:b1773. CrossRef

7. Sanzén L, Carlsson AS, Josefsson G, Lindberg LT. Revision operations on infected total hip arthroplasties. Two-to nine-year follow-up study. Clin Orthop Relat Res 1988;(229):165-72.

8. Langlais $\mathrm{F}$. Can we improve the results of revision arthroplasty for infected total hip replacement? J Bone Joint Surg $\mathrm{Br}$ 2003;85(5):637-40.

9. Luu A, Syed F, Raman G, Bhalla A, Muldoon E, Hadley S, Smith E, Rao M. Two-stage arthroplasty for prosthetic joint infection: a systematic review of acute kidney injury, systemic toxicity and infection control. J Arthroplasty 2013;28(9):1490-8.e1. CrossRef

10. De Man FH, Sendi P, Zimmerli W, Maurer TB, Ochsner PE, Ilchmann T. Infectiological, functional, and radiographic outcome after revision for prosthetic hip infection according to a strict algorithm. Acta Orthop 2011;82(1):27-34. CrossRef

11. Gehrke T, Kendoff D. Peri-prosthetic hip infections: in favour of one-stage. Hip Int 2012;22 Suppl 8:S40-5. CrossRef

12. Klouche S, Leonard P, Zeller V, Lhotellier L, GraffW, Leclerc P, Mamoudy P, Sariali E. Infected total hip arthroplasty revision: one or two-stage procedure? Orthop Traumatol Surg Res 2012;98(2):144-50. CrossRef

13. Oussedik SI, Dodd MB, Haddad FS. Outcomes of revision total hip replacement for infection after grading according to a standard protocol. J Bone Joint Surg Br 2010;92(9):1222-6. CrossRef

14. Winkler H, Stoiber A, Kaudela K, Winter F, Menschik F. One stage uncemented revision of infected total hip replacement using cancellous allograft bone impregnated with antibiotics. J Bone Joint Surg Br 2008;90(12):1580-4. CrossRef

15. Bozic KJ, Ries MD. The impact of infection after total hip arthroplasty on hospital and surgeon resource utilization. J Bone Joint Surg Am 2005;87(8):1746-51.

16. Klouche S, Sariali E, Mamoudy P. Total hip arthroplasty revision due to infection: a cost analysis approach. Orthop Traumatol Surg Res 2010;96(2):124-32. CrossRef

17. Merollini KM, Crawford RW, Graves N. Surgical treatment approaches and reimbursement costs of surgical site infections post hip arthroplasty in Australia: a retrospective analysis. BMC Health Serv Res 2013;13:91. CrossRef

18. Wolf CF, Gu NY, Doctor JN, Manner PA, Leopold SS. Comparison of one and two-stage revision of total hip arthroplasty complicated by infection: a Markov expected-utility decision analysis. J Bone Joint Surg Am 2011;93(7):631-9. CrossRef

19. Atkins BL, Bowler IC. The diagnosis of large joint sepsis. J Hosp Infect 1998;40(4):263-74.

20. Frommelt L. Diagnosis and treatment of foreign-bodyassociated infection in orthopaedic surgery. Orthopade 2009; 38(9):806-11. CrossRef 
21. Elek SD, Conen PE. The virulence of Staphylococcus pyogenes for man; a study of the problems of wound infection. Br J Exp Pathol 1957;38(6):573-86.

22. Zimmerli W, Lew PD, Waldvogel FA. Pathogenesis of foreign body infection. Evidence for a local granulocyte defect. J Clin Invest 1984;73(4):1191-200.

23. Costerton JW, Stewart PS, Greenberg EP. Bacterial biofilms: a common cause of persistent infections. Science 1999;284(5418):1318-22.

24. Fitzgerald RH Jr, Nolan DR, Ilstrup DM, Van Scoy RE, Washington JA 2nd, Coventry MB. Deep wound sepsis following total hip arthroplasty. J Bone Joint Surg Am 1977;59(7):847-55.

25. Tsukayama DT, Estrada R, Gustilo RB. Infection after total hip arthroplasty. A study of the treatment of one hundred and six infections. J Bone Joint Surg Am 1996;78(4):512-23.

26. Toms AD, Davidson D, Masri BA, Duncan CP. The management of peri-prosthetic infection in total joint arthroplasty. J Bone Joint Surg Br 2006;88(2):149-55.

27. Della Valle C, Parvizi J, Bauer TW, Dicesare PE, Evans RP, Segreti J, Spangehl M, Watters WC 3rd, Keith M, Turkelson CM, Wies JL, Sluka P, Hitchcock K; American Academy of Orthopaedic Surgeons. Diagnosis of periprosthetic joint infections of the hip and knee. J Am Acad Orthop Surg 2010;18(12):760-70.

28. Schäfer P, Fink B, Sandow D, et al. Prolonged bacterial culture to identify late periprosthetic joint infection: a promising strategy. Clin Infect Dis 2008;47(11):1403-9. CrossRef

29. Della Valle CJ, Sporer SM, Jacobs JJ, Berger RA, Rosenberg AG, Paprosky WG. Preoperative testing for sepsis before revision total knee arthroplasty. J Arthroplasty 2007;22(6 Suppl 2):90-3.

30. Ghanem E, Parvizi J, Burnett RS, Sharkey PF, Keshavarzi $\mathrm{N}$, Aggarwal A, Barrack RL. Cell count and differential of aspirated fluid in the diagnosis of infection at the site of total knee arthroplasty. J Bone Joint Surg Am 2008;90(8):163743. CrossRef

31. Trampuz A, Hanssen AD, Osmon DR, Mandrekar J, Steckelberg JM, Patel R. Synovial fluid leukocyte count and differential for the diagnosis of prosthetic knee infection. Am J Med 2004;117(8):556-62.

32. Fink B, Makowiak C, Fuerst M, Berger I, Schäfer P, Frommelt $\mathrm{L}$. The value of synovial biopsy, joint aspiration and C-reactive protein in the diagnosis of late peri-prosthetic infection of total knee replacements. J Bone Joint Surg Br 2008;90(7):8748. CrossRef

33. Fink B, Vogt $S$, Reinsch $M$, Büchner $H$. Sufficient release of antibiotic by a spacer 6 weeks after implantation in two-stage revision of infected hip prostheses. Clin Orthop Relat Res 2011;469(11):3141-7. CrossRef

34. Hanssen AD, Spangehl MJ. Practical applications of antibiotic-loaded bone cement for treatment of infected joint replacements. Clin Orthop Relat Res 2004;(427):79-85.
35. Gehrke T, Frommelt L, G. vF, editors. Pharmacokinetic Study of a Gentamycin/Clindamycin Bone Cement Used in One Stage Revision Arthroplasty. In: Bone Cement and Cementing Technique. Springer; 1998.

36. Trampuz A, Osmon DR, Hanssen AD, Steckelberg JM, Patel R. Molecular and antibiofilm approaches to prosthetic joint infection. Clin Orthop Relat Res 2003;(414):69-88.

37. Wahlig $H$, Dingeldein $E$, Buchholz HW, Buchholz $M$, Bachmann F. Pharmacokinetic study of gentamicin-loaded cement in total hip replacements. Comparative effects of varying dosage. J Bone Joint Surg Br 1984;66(2):175-9.

38. Kordelle J, Klett R, Stahl U, Hossain H, Schleicher I, Haas H. Infection diagnosis after knee-TEP-implantation. Z Orthop Ihre Grenzgeb 2004;142(3):337-43.

39. Frommelt L. Periprosthetic infection: bacteria and the interface between prosthesis and bone. In: Learmonth ID, editor. Interfaces in total hip arthroplasty. London: Springer Verlag, 153-61.

40. SpangehI MJ, Masri BA, O'Connell JX, Duncan CP. Prospective analysis of preoperative and intraoperative investigations for the diagnosis of infection at the sites of two hundred and two revision total hip arthroplasties. J Bone Joint Surg Am 1999;81(5):672-83.

41. Frommelt L. Interfaces in Total Hip Arthroplasty. Ian D. Learmonth, editor. London: Springer -Verlag Ltd.; 2000. p.153-61.

42. Buechel FF, Femino FP, D'Alessio J. Primary exchange revision arthroplasty for infected total knee replacement: a long-term study. Am J Orthop (Belle Mead NJ) 2004;33(4):190-8.

43. Hoad-Reddick DA, Evans CR, Norman P, Stockley I. Is there a role for extended antibiotic therapy in a two-stage revision of the infected knee arthroplasty? J Bone Joint Surg $\mathrm{Br}$ 2005;87(2):171-4.

44. Mangram AJ, Horan TC, Pearson ML, Silver LC, Jarvis WR. Guideline for prevention of surgical site infection, 1999. Hospital Infection Control Practices Advisory Committee. Infect Control Hosp Epidemiol 1999;20(4):250-78.

45. Azzam K, McHale K, Austin M, Purtill JJ, Parvizi J. Outcome of a second two-stage reimplantation for periprosthetic knee infection. Clin Orthop Relat Res 2009;467(7):1706-14. CrossRef

46. Haleem AA, Berry DJ, Hanssen AD. Mid-term to long-term followup of two-stage reimplantation for infected total knee arthroplasty. Clin Orthop Relat Res 2004;(428):35-9.

47. Kilgus DJ, Howe DJ, Strang A. Results of periprosthetic hip and knee infections caused by resistant bacteria. Clin Orthop Relat Res 2002;(404):116-24.

48. Goldman RT, Scuderi GR, Insall JN. 2-stage reimplantation for infected total knee replacement. Clin Orthop Relat Res 1996;(331):118-24.

49. Silva M, Tharani R, Schmalzried TP. Results of direct exchange or debridement of the infected total knee arthroplasty. Clin Orthop Relat Res 2002;(404):125-31. 